\title{
Modificaciones biofísicas durante el Fenómeno El Niño y su correlación con la epidemia de encefalitis viral en Talara, Perú 1997-1998
}

\author{
Biophysical modifications during the El Niño phenomenon and correlation with encephalitis \\ virus epidemic in Talara, Peru 1997-1998
}

\author{
Mónica Briceño Aliaga' \\ 'Magister en Salud Pública, Médico Pediatra, Profesor auxiliar, Departamento de ciencias dinámicas sección química, Facultad de Medicina \\ Universidad Nacional Mayor de San Marcos, Lima, Perú.
}

An Fac med. 2016;77(1):75-6 / http://dx.doi.org/10.15381/anales.v77i1.11615

\section{SEÑOR EDITOR:}

El Fenómeno El Niño se presenta cada 4 a 7 años; forma parte de un evento natural océano atmosférico conocido como ENSO (Oscilation southern-El Niño).

En condiciones normales, en el lado oeste del Océano Pacifico existe una temperatura del mar de $29^{\circ} \mathrm{C}$ y un sistema de baja presión atmosférica en Darwin- Australia; mientras que en el lado este hay un sistema de alta presión en Papeete-Tahití y a nivel de las costas del Perú y Ecuador, donde la temperatura del mar es de 19 a $23^{\circ} \mathrm{C}$. Las aguas frías del este del Pacifico condicionan en la atmósfera zonas de alta presión y las aguas cálidas zonas de baja presión; la diferencia de presiones produce que los vientos alisios viajen de este a oeste, arrastrando aguas superficiales y produciendo un fenómeno de afloramiento, por el cual, las aguas más frías del fondo del mar salen a nivel superficial. Las aguas profundas son ricas en sales y micronutrientes para la formación de fitoplancton, base de la cadena alimenticia de los peces. El fitoplancton vive en las capas superiores iluminadas; es importante en los procesos de interacción océano-atmosférica, modula el calor por la producción del dimetil sulfuro (DMS); influye en la química del océano al usar el dióxido de carbono disuelto en el agua para producir azúcares y oxígeno. Utiliza nutrientes inorgánicos como nitrógeno, fósforo, silicio, hierro para sintetizar moléculas complejas como proteínas.
Durante el Fenómeno el Niño se produce un incremento de la temperatura superficial del mar a nivel este del Pacifico. El aire sobre esa zona se calienta, eleva, humedece, condensa, produciendo formación de nubes. El aumento de la temperatura del aire ocasiona disminución de la presión atmosférica en el lado este del Pacifico, en relación a la presión en Australia, condicionando una diferencia de presiones conocida como Índice de oscilación del sur. La intensidad de los vientos disminuye, se modifican las zonas de mayor humedad relativa del aire; se incrementan las lluvias en el norte del Perú y sur del Ecuador. No existe afloramiento, se alteran los contenidos de sales y micronutrientes, existe profundización de peces o desplazamiento hacia el sur. El fitoplancton varía, porque depende de una concentración exacta de salinidad y temperatura ${ }^{(1)}$.

El Fenómeno El Niño 1997-1998, de intensidad inusualmente alta, con efectos regionales y mundiales, produjo en la costa del Perú aumento de la temperatura ambiental y de las lluvias, destrucción de caminos, carreteras, elevación de los cuadros febriles hipertérmicos en los centros de salud. Durante ese verano del 98, en la provincia de Talara, departamento de Piura, el Hospital integrado IPSS-MINSA (Instituto Peruano de Seguridad Social-Ministerio de Salud) reportó incremento de muertes infantiles, asociado a una entidad clínica de presentación inusual y rápida evolución. Esta situación con- vocó la participación de instituciones nacionales e internacionales. Entre los meses de enero y febrero, la Universidad Nacional Mayor de San Marcos, a través de la Unidad de Posgrado de Pediatría, evaluó 26 niños hospitalizados. El 58\% (15/26) tenía entre 1 y 2 años de edad. La secuencia clínica inició con signos y/o síntomas de mucosa respiratoria, digestiva o manifestaciones generales, seguido por compromiso sistémico y signos neurológicos como irritabilidad, movimientos involuntarios, convulsiones o coma. Los hallazgos del examen físico fueron: fiebre, congestión conjuntival, congestión faríngea, adenomegalias, estertores pulmonares, taquicardia, hepatomegalia, irritabilidad o somnolencia, hipertonía y compromiso neurológico en el 100\% de los casos, alteración de la conciencia en grados variables según la escala de disfunción cerebral de Lovejoy.

Se realizaron 18 hemocultivos y 20 cultivos de líquido cefalorraquídeo, resultando negativos a bacterias. Se encontró hiponatremia en 9 de 18 casos, ninguno tuvo hipernatremia. La tasa de letalidad fue de 23\% (6/26). De los 20 pacientes que fueron dados de alta, cuatro quedaron con secuelas neurológicas. La evaluación de casos llegó a la conclusión que fue una epidemia de infecciones virales con encefalitis, que provocó edema cerebral, siendo la causa de muerte de seis de los niños tratados y probablemente la causa de las muertes reportadas en los meses anteriores, desde que se inició la epide- 
mia de infecciones virales y que fueron reportados al MINSA como golpe de calor, hipernatremia, enfermedad diarreica aguda e infecciones respiratorias agudas con convulsión febril (2-4). $\mathrm{He}$ mos encontrado casos clínicos similares a los reportados en países como Taiwán, Malasia, que realizaron estudios anatomopatológicos, serológicos y que precisaron los agentes virales ${ }^{(5-6)}$.

Los cambios en la temperatura y la humedad condicionan cambios en plagas y agentes causales de enfermedad. En condiciones de cambios climáticos los virus emergen, dando lugar a epidemias virales, encefalitis. Los virus han existido por millones de años, se hacen evidentes cuando las condiciones climáticas cambian ${ }^{(7-8)}$. Investigaciones europeas sostienen que son las condiciones socioeconómicas (desindustrialización, modificación de uso de tierras, descanso, pobreza) las que tienen un rol preponderante en la reaparición de enfermedades ${ }^{(9)}$. Los virus, como toda forma viviente, cuenta con mecanismos de supervivencia; uno de ellos es la coevolución o simbiosis agresiva, que permite utilizar la maquinaria energética de la célula, logrando reproducirse o mantenerse de manera latente. La célula puede morir; si sobrevive, acepta la persistencia de la infección viral debido a que ello confiere algún tipo de ventaja. Las nuevas epidemias se activan cuando existe intrusión del hombre en los ciclos simbióticos huésped virus; diferentes factores pueden aumentar o disminuir esta interacción ${ }^{(10)}$.

Los cambios biofísicos de los ecosistemas en las costas del Perú, en el mar y en la atmósfera durante el Fenómeno El Niño 97-98 ocasionaron la ruptura del equilibrio entre humedad del aire, temperatura del océano, sales minerales, fitoplancton; bacterias, peces; vectores y población. El incremento de las precipitaciones pluviales, sus efectos en la infraestructura y saneamiento en la Provincia de Talara contribuyeron a crear las condiciones para el incremento de muertes infantiles por encefalitis debido a la aparición de una epidemia de infecciones virales ${ }^{(2-4)}$.

La información científica multidisciplinaria disponible de el Fenómeno El Niño debe servir a nuestras autoridades para la toma de decisiones oportunas en la prevención de sus efectos, de acuerdo a las lecciones aprendidas en el verano de 1998.

\section{REFERENCIAS BIBLIOGRÁFICAS}

1. Delecluse P. Heurs et Maleurs de la prévisión D'El niño. La Recherche. Mars 1998;307:72-7.

2. Del Águila A, Briceño M Análisis de la epidemia de muertes infantiles en Talara durante el Fenómeno el Niño de 1997-1998 ¿estamos preparados para enfrentar otra? An Fac med. 2007;68(2):193-202.

3. Alvarado R, Briceño M. Encefalitis viral en niños menores de 5 años durante el Fenómeno El Niño en Talara febrero de 1998. Tesis para optar el Título de especialista en Pediatria, Universidad Nacional Mayor de San Marcos, Lima, Perú, 2001.

4. Aburto F, Del Águila A. El Fenómeno El Niño y los procesos Infecciosos virales como causa de morbimortalidad en el brote epidémico en niños de la provincia de Talara Marzo 1998. Tesis para optar el Título de especialista en Pediatria, Universidad Nacional Mayor de San Marcos, Lima, Perú, 2002.

5. Wang SM, Liu CC, Tseng HW, Wang JR, Huang CC Chen YJ, Yang YJ, Lin SJ, Yeh TF. Clinical spectrum of enterovirus 71 infection in children in Southerm Taiwan, with an emphasis on neurological complications. Clin Infect Dis.1999 Jul;29(1):184-90.

6. Chan L, Parashar U, Lye M, Ong F, Zaki S, Alexander J, Ho K, et al. Deaths of children during and outbreak of hand, foot and mouth disease in Sarawak, Maylasia: clinical and pathological characteristics of the disease. Clin Infect Dis. 2000;31(3):678-83. doi:10.1086/314032.

7. Brown K. Do disease cycles follow changes in weather? Bio Science. 1996 Jul/Aug;46(7):479-81.

8. Anyamba A, Chretien JP, Small J, Tucker CJ, Linticum KJ. Developing global climate anomalies suggest potential disease risks for 2006-2007. Int J Health Geology. 2006 Dec 28;5:60.

9. Klinger $\mathrm{C}$. Le changement climatique favorise-t-il l'emergence de maladies? La Recherché. Mars 2010;439:34-5.

10. Ryan F. The aggressive symbiont. En: Virus $X$ London: Harper Collins Publishers. 1996:273- 89.

Carta al Editor recibida el 13 de agosto de 2015.

Correspondencia:

Dra. Mónica Briceño Aliaga

Correo electrónico: monicris12000@yahoo.com 